ARTICLE

DOI: $10.1038 / \mathrm{s} 41467-018-03324-7$

\title{
Formation of size-dependent and conductive phase on lithium iron phosphate during carbon coating
}

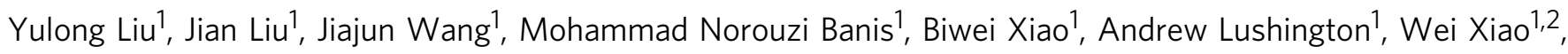
Ruying $\mathrm{Li}^{1}$, Tsun-Kong Sham², Guoxian Liang ${ }^{3} \&$ Xueliang Sun ${ }^{1}$

Carbon coating is a commonly employed technique for improving the conductivity of active materials in lithium ion batteries. The carbon coating process involves pyrolysis of organic substance on lithium iron phosphate particles at elevated temperature to create a highly reducing atmosphere. This may trigger the formation of secondary phases in the active materials. Here, we observe a conductive phase during the carbon coating process of lithium iron phosphate and the phase content is size, temperature, and annealing atmosphere dependent. The formation of this phase is related to the reducing capability of the carbon coating process. This finding can guide us to control the phase composition of carbon-coated lithium iron phosphate and to tune its quality during the manufacturing process.

\footnotetext{
${ }^{1}$ Department of Mechanical and Materials Engineering, Western University, London, ON N6A 5B9, Canada. ${ }^{2}$ Department of Chemistry, Western University, London, ON N6A 5B7, Canada. ${ }^{3}$ Johnson Matthey, 280 Ave. Liberté, Candiac, QC J5R 6X1, Canada. Correspondence and requests for materials should be addressed to G.L. (email: Guoxian.Liang@matthey.com) or to X.S. (email: xsun@eng.uwo.ca)
} 
S ince the first report in 1997, olivine $\mathrm{LiFePO}_{4}$ (LFP) as an environmentally benign and a safer cathode material has been widely studied in the field of energy storage ${ }^{1}$. Considerable efforts have been devoted toward improving the intrinsic low electronic and ionic conductivity of this material ${ }^{2-4}$. Surface carbon coating is often used to increase the electrical conductivity of LFP and has proven to be an effective strategy ${ }^{4,5}$. This has led to significant progress for the wide-spread application of LFP in commercial lithium ion batteries during the last two decades ${ }^{6-8}$. However, an in-depth understanding of surface chemistry changes during the carbon coating process remains elusive. Carbon coating usually involves a strong reducing environment and often requires high temperature. This increases the reaction kinetics between the surface of LFP and the supplied carbon ${ }^{9}$. As a result, secondary phases will form on the surface, thereby altering the electronic/ionic conductivity of $\mathrm{LFP}^{10-14}$. Previously, a $\mathrm{Fe}_{2} \mathrm{P}_{2} \mathrm{O}_{7}$ secondary phase was observed on the surface of hydrothermally synthesized LFP. The origin of such impurity phase formation is ascribed to more $\mathrm{Fe}_{\mathrm{Li}}$ antisite formed at lower temperature synthesis than high temperature solid-state reactions ${ }^{15-17}$. The formation of another secondary phase, iron phosphide, has been shown to be closely related to the annealing procedure employed and undoubtly influence the physical properies of LFP. Annealing the LFP at different temperatures/ atmosphere, iron phosphides $\left(\mathrm{FeP}, \mathrm{Fe}_{2} \mathrm{P}\right.$, and $\left.\mathrm{Fe}_{3} \mathrm{P}\right)$ were detected with $\mathrm{XRD}^{18,19}$. By controlling the content of the iron phosphides, the long-term cycle performance and rate performance of carboncoated LFP was improved ${ }^{20-22}$. In addition, work on the carbon quality of LFP suggested that more graphitic carbon layers were easily formed with iron phosphide inside $\mathrm{LFP}^{9}$. Because the carbon coating process on LFP is a multi-component system at small scale, it is very difficult to define the presence of secondary phase, to map the distribution of secondary phase, to record the change of secondary phase, and the control of secondary phase. Therefore, understanding the formation mechanism for emergence of secondary phases would be highly beneficial, especially for LFP manufacturers.

In our previous study, we found interface reactions occurred between the carbon layer and LFP during the carbon coating process. The evaporation of lithium at high temperature results in the formation of an inert impurity phase $\mathrm{Fe}_{2} \mathrm{P}_{2} \mathrm{O}_{7}$. With the help of advanced techniques, we clearly recorded the location and distribution of surface phases and hypothesized the formation of $\mathrm{Fe}_{2} \mathrm{P}_{2} \mathrm{O}_{7}{ }^{23}$. Our next study shows that the amount of the $\mathrm{Fe}_{2} \mathrm{P}_{2} \mathrm{O}_{7}$ phase can be controlled, and even be fully removed by tuning parameters applied during the carbon coating process. However, removal of a negative secondary phase in LFP is not the only objective to produce high quality LFP. It would also be essential to improve the electrochemical performance of LFP by tuning electronic conductivity. There have been numerous attempts to increase the electronic conductivity of LFP, such as forming a percolating carbon network on the surface of $\mathrm{LFP}^{12-14}$. Furthermore, coating formed on the LFP surface to enhance the lithium ion conductivity, by forming off-stoichiometry composition, is of great interest. Surface engineering on the LFP with the aim of improving the electrochemical performance has been a very promising direction in this field ${ }^{14,24-26}$. Our research goal is to engineer the chemical composition of LFP surface via carbon coating. This method may be effective in creating an appropriate off-stoichiometry LFP with uniform carbon coating on the surface. Such a unique carbon-coated LFP materials could simultaneously resolve both low lithium ion conductivity and electronic conductivity. Due to the highly complex nature of interface reaction, there is no direct way to visualize and monitor the surface chemistry change during carbon coating process. Recently, melt-casting has been shown to be a promising technique in preparing $\mathrm{LFP}^{27,28}$. After polishing the surface of melt-casted LFP ingot, a large flat surface can be obtained. A mirror surface takes the advantage of visualization of detailed surface chemistry changes during carbon coating process, which would greatly help us to understand the reaction at the interface ${ }^{9}$.

Here in this work, LFP ingot and LFP particles, with different sizes, have been used to demonstrate and present a sizedependent conductive secondary phase formation during carbon coating. Furthermore, surface phase changes are correlated to temperature and reducing atmosphere. Therefore, formation of secondary phase is controlled by LFP particle size, annealing temperature, and reducing atmosphere, simultaneously. LFP particles with appropriate amount of conductive phase are obtained by carefully tuning coating parameters during the carbon coating process. The improved electrochemical performance of LFP materials with conductive phase suggests that such secondary phase has a positive influence. From a thermodynamic point of view, we propose a unified mechanism that can be used to describe the formation of $\mathrm{Fe}_{2} \mathrm{P}$ phase under different circumstances. In particular, we use LFP ingot sample to demonstrate the direct visualization of this phase change mechanism during carbon coating. Our study on carbon-coated LFP may also enlighten the interests on the interface chemistry research, especially, reactions of insulating materials in reducing atmosphere.

\section{Results}

Surface phase formation. As shown in Fig. 1, an intriguing phenomenon of spherical-like phase growth can be seen on the surface of the carbon-coated LFP ingot at $900^{\circ} \mathrm{C}$, and is distinctively different in morphology from the underlying matrix . A close-up view shows that the spherical-like phase is not uniform, with different sizes and shapes observed at various locations. Using energy-dispersive X-ray spectroscopy (EDS) mapping, this surface phase was assigned as an Fe-rich phase covered by a layer of carbon. In addition, a region enriched in phosphorus and oxygen suggests the presence of lithium phosphates. We propose that these surface changes are correlated to the carbon coating process as these observations are not found under $\mathrm{H}_{2}$ reduction or pure Ar atmospheres, where no carbon is presented (Supplementary Fig. 1).

Characterization of the size-dependent surface phase. To verify our findings, we further extended our study to powder samples with varying sizes. LFP particles ranging from micro-sized (19 $\mu \mathrm{m})$ to nano-sized $(60 \mathrm{~nm})$ were obtained by ball milling LFP ingot sample (size distribution can be found in Supplementary Fig. 2). Figure 2a reveals XRD patterns of carbon-coated LFP with different sizes. Small peaks in the range of $38-48^{\circ}$ (gray area) are clearly observed for all LFP particles, and can be assigned to $\mathrm{Fe}_{2} \mathrm{P}$ (JCPDS No 85-1725). As LFP particle size decreases, peak intensities for $\mathrm{Fe}_{2} \mathrm{P}$ intensify (See the inset in Fig. 2a). To support the evidence for a size-dependent relationship on the formation of $\mathrm{Fe}_{2} \mathrm{P}$, two types of LFP samples with size of $560 \mathrm{~nm}$ and $60 \mathrm{~nm}$ were characterized using transmission electron microscope (TEM) following carbon coating at $900^{\circ} \mathrm{C}$. It is seen that the size distributions of $560 \mathrm{~nm}$ and $60 \mathrm{~nm}$ LFP particles has grown due to high temperature (Supplementary Fig. 3). Interestingly, Fig. 2b displays small spherical particles adjacent to larger LFP particles. Selected Area Electron Diffraction (SAED) pattern of that particulate are consistent with $\mathrm{Fe}_{2} \mathrm{P}$ [001]. Moreover, the amount of $\mathrm{Fe}_{2} \mathrm{P}$ phase formed on the $60 \mathrm{~nm}$ LFP is bigger than that found for $560 \mathrm{~nm}$ LFP. This provides good evidence for a correlation existing between $\mathrm{Fe}_{2} \mathrm{P}$ phase formation and LFP particle size. From the inset of the HRTEM images in Supplementary Fig. 4, 
a

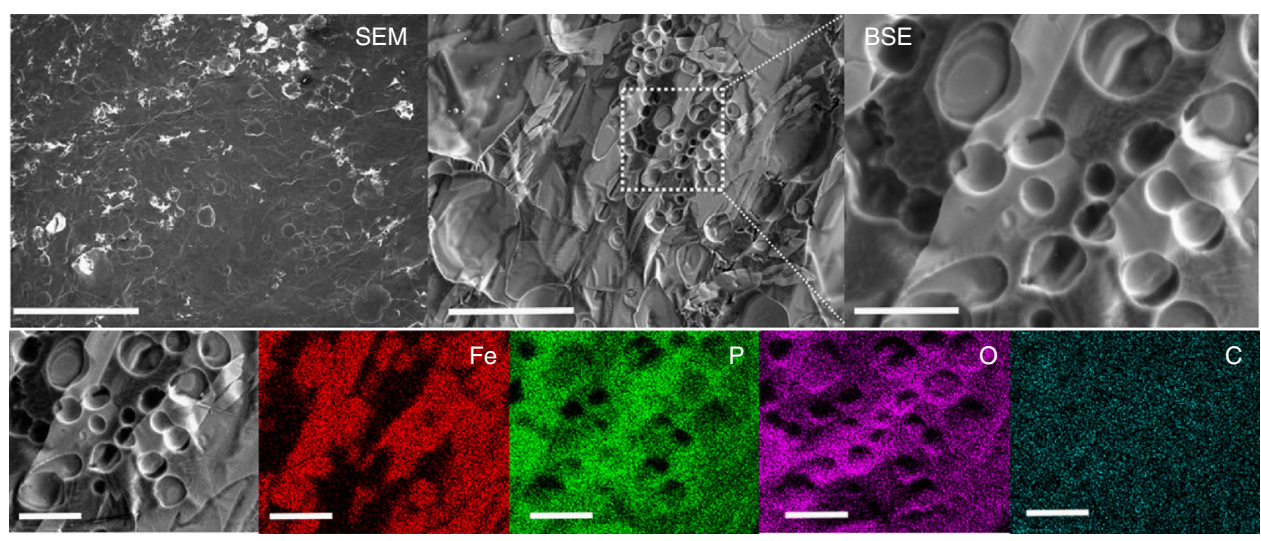

b

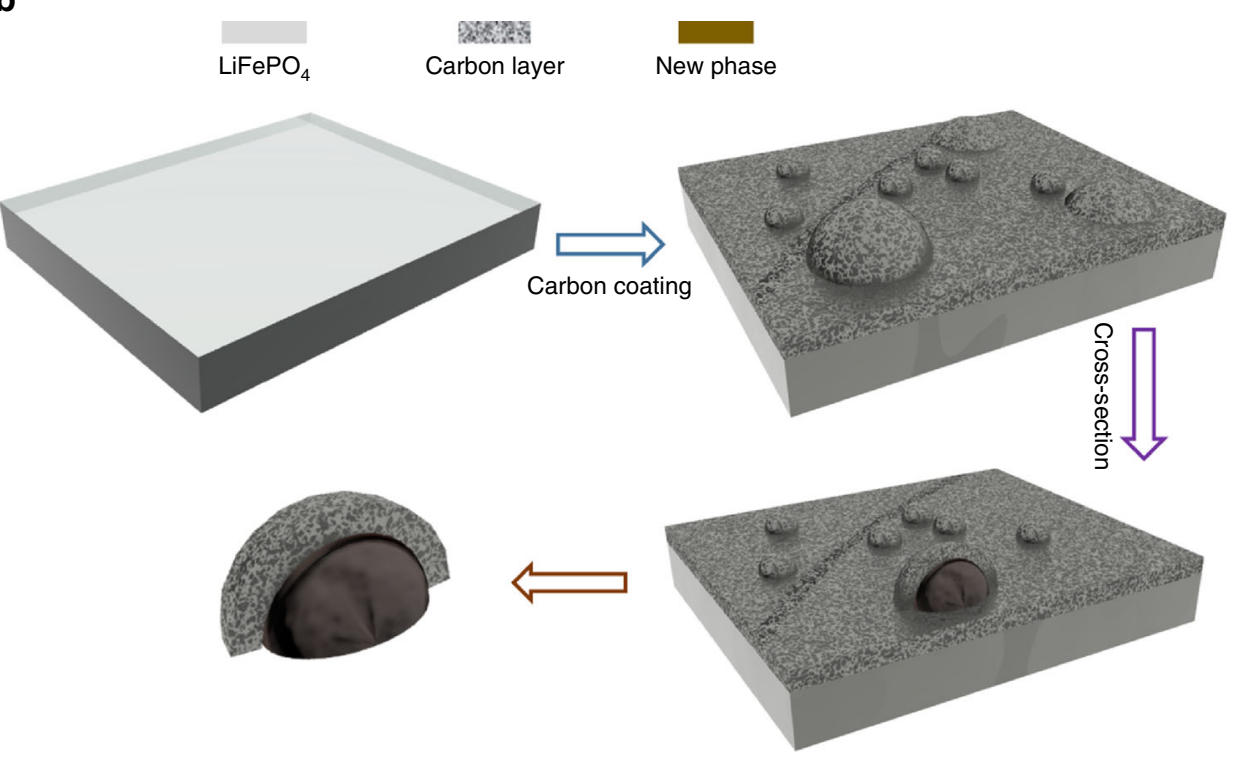

Fig. 1 Surface conductive phase formation during carbon coating process. a Upper panel: SEM images (left side), BSE images (middle and right); lower panel: EDS mapping of surface conductive phase formation on $\mathrm{LiFePO}_{4}$. $\mathbf{b}$ Schematic representation of new phase formation on $\mathrm{LiFePO}$. Scale bar, $1 \mathrm{~mm}$ (SEM image), $200 \mu \mathrm{m}$ (BSE), and $50 \mu \mathrm{m}$ (right side BSE and lower panel EDS images)

the carbon coating on $\mathrm{Fe}_{2} \mathrm{P}$ is about $6 \mathrm{~nm}$ and is thicker than the carbon coating on LFP, which is around $3 \mathrm{~nm}$. The smaller size $\mathrm{Fe}_{2} \mathrm{P}$ with thicker carbon coating would be beneficial in improving LFP conductivity.

To get a clear evidence of phase change process, carbon coating was directly observed on powder LFP (nano size LFP) by in-situ SEM observations combined with injection of carbon precursor ${ }^{23}$. Following carbon precursor injection, the particles begin to aggregate and then shrink, ending with a melted product. Using a higher magnification SEM (Supplementary Fig. 5), the formation of secondary phase on the surface of primary LFP particles can be seen.

Temperature and atmospheric dependent phenomenon. The $\mathrm{Fe}_{2} \mathrm{P}$ new phase could be easily formed at high temperature carbon coating on LFP particles. Figure 3a displays the formation of a new phase following carbon coating of $60 \mathrm{~nm}$ LFP at different temperatures. The XRD pattern reveals the formation of $\mathrm{Fe}_{2} \mathrm{P}$ begins at $850{ }^{\circ} \mathrm{C}$ and increases in peaks intensity at $900{ }^{\circ} \mathrm{C}$, suggesting that phase formation of $\mathrm{Fe}_{2} \mathrm{P}$ is temperature dependent. If we extend the LFP particle size to $560 \mathrm{~nm}$ and $19 \mu \mathrm{m}, 560 \mathrm{~nm}$ LFP shows size-dependent phenomenon as $60 \mathrm{~nm}$ LFP (Supplementary Fig. 4), but the $\mathrm{Fe}_{2} \mathrm{P}$ phase formation is delayed to $900^{\circ} \mathrm{C}$
(Supplementary Fig. 5). This suggests that the formation of $\mathrm{Fe}_{2} \mathrm{P}$ phase is related to both size and temperature.

Apart from temperature, annealing atmosphere is another critical factor during carbon coating of LFP. To investigate the influence of annealing atmosphere, we intentionally introduced $\mathrm{H}_{2}$ gas during the carbon coating process and observed the corresponding surface phase changes. Figure $3 \mathrm{~b}$ displays the atmospheric dependent nature of $\mathrm{Fe}_{2} \mathrm{P}$ impurity phase formation. Carbon coating is performed on $60 \mathrm{~nm}$ LFP in the temperature range of $600-800{ }^{\circ} \mathrm{C}$ for $\mathrm{Ar} / \mathrm{H}_{2}$. XRD patterns demonstrate that using an $\mathrm{Ar} / \mathrm{H}_{2}$ reducing atmosphere, a critical temperature of $700{ }^{\circ} \mathrm{C}$ is required for the formation of $\mathrm{Fe}_{2} \mathrm{P}$ phase rather than the $850{ }^{\circ} \mathrm{C}$ that is required in a pure Ar atmosphere. For $560 \mathrm{~nm}$ LFP, $\mathrm{Fe}_{2} \mathrm{P}$ phase formation temperature reduced to $700^{\circ} \mathrm{C}$, as well as in $\mathrm{Ar} / \mathrm{H}_{2}$ (Supplementary Fig. 6). Even for $19 \mu \mathrm{m}$ LFP particles, $\mathrm{Fe}_{2} \mathrm{P}$ phase formation temperature was found to occur at $800^{\circ} \mathrm{C}$, a lower temperature than in pure $\operatorname{Ar}\left(900^{\circ} \mathrm{C}\right.$ ) (Supplementary Fig. 7).

To further identify the $\mathrm{Fe}_{2} \mathrm{P}$ phase distribution in LFP particles, surface morphology was examined following carbon coating at $700{ }^{\circ} \mathrm{C}$. SEM images, shown in Supplementary Fig. 8, demonstrate the formation of large crystals on $60 \mathrm{~nm}$ LFP following carbon coating in a more reducing environment $\left(\mathrm{Ar} / \mathrm{H}_{2}\right)$. In contrast, no 
a
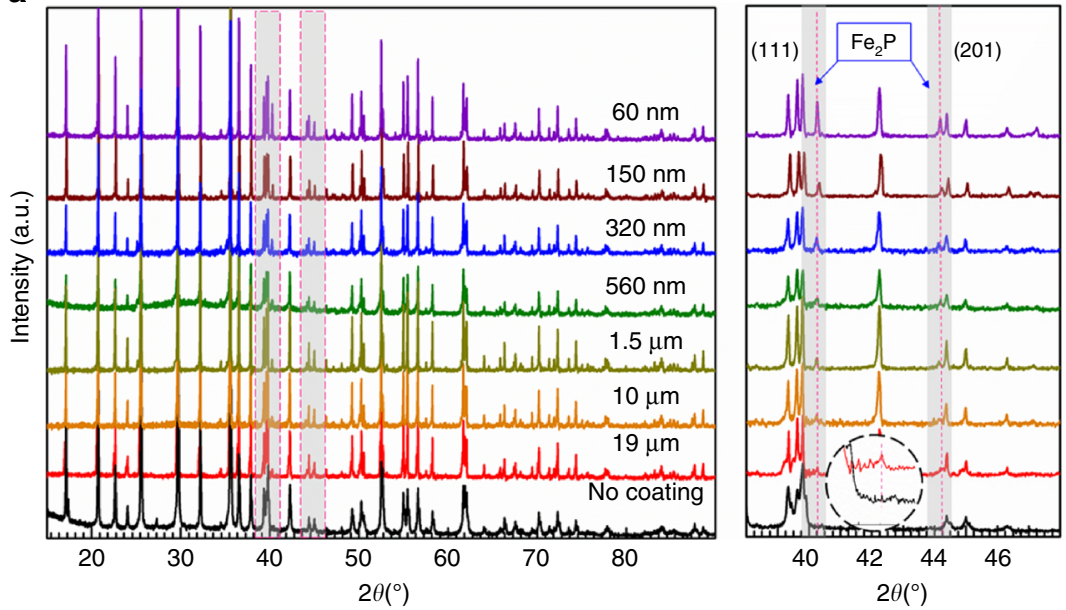

b

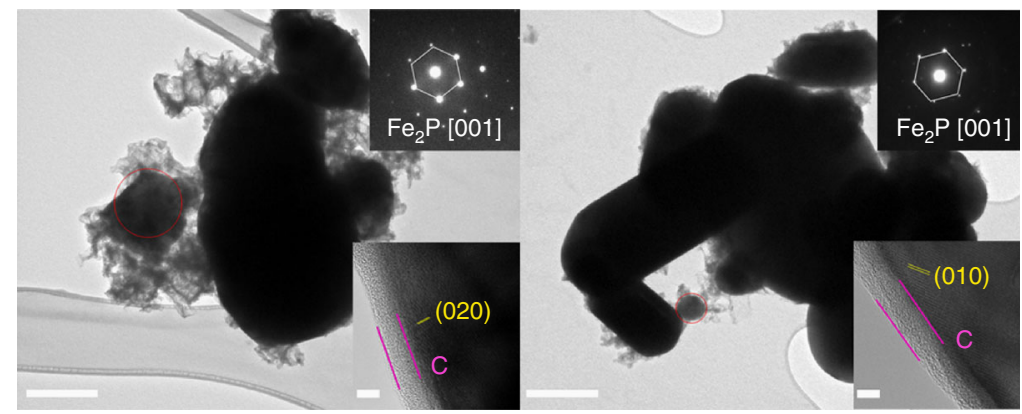

Fig. 2 Size-dependent properties of $\mathrm{Fe}_{2} \mathrm{P}$ phase formation. a XRD pattern of different size LFP particles after carbon coating at $900{ }^{\circ} \mathrm{C}$. $\mathbf{b} \mathrm{HRTEM} F \mathrm{e}_{2} \mathrm{P}$ phase for $60 \mathrm{~nm} \mathrm{LFP}$ and $560 \mathrm{~nm}$ LFP annealed at $900^{\circ} \mathrm{C}$. Inset shows the SAED pattern of $\mathrm{Fe}_{2} \mathrm{P}$ phase and HRTEM images of Fe $2 \mathrm{P}$ phase. Scale bar, 500 $\mathrm{nm}$ in TEM, $5 \mathrm{~nm}$ in HRTEM

such particles are observed for $60 \mathrm{~nm}$ LFP coated in Ar gas. To obtain detailed information about the particles, we picked $60 \mathrm{~nm}$ LFP in $\mathrm{Ar}$ and $\mathrm{Ar} / \mathrm{H}_{2}$ for TEM characterization. A large rod-like crystal can be seen for $60 \mathrm{~nm}$-coated LFP in a reducing atmosphere. Based on the SAED diffraction pattern, this feature can be assigned to hexagonal $\mathrm{Fe}_{2} \mathrm{P}$ phase (As shown in Fig. $3 \mathrm{c}$ ). Nevertheless, no such crystal formation was observed for $60 \mathrm{~nm}$ LFP coated in Ar gas, and is further supported by clear polycrystalline LFP diffraction rings. From the HRTEM images in Fig. $3 c$, the rod-like $\mathrm{Fe}_{2} \mathrm{P}$ phase is shown to be covered by a 2 nm-thick carbon coating, while the nano-LFP is covered with thicker carbon coating $(5 \mathrm{~nm})$. Thus, larger $\mathrm{Fe}_{2} \mathrm{P}$ phase with thin carbon coating is observed for $60 \mathrm{~nm}$ LFP after carbon coating in $\mathrm{Ar} / \mathrm{H}_{2}$

Electrochemical performance of LFP with new phase. In order to verify the electronic conductivity improvement brought on by $\mathrm{Fe}_{2} \mathrm{P}$, electrochemical performance of LFP was evaluated. As discussed above, $\mathrm{Fe}_{2} \mathrm{P}$ phase formation in a reducing environment results in the formation of large crystals covered by a thin coating of carbon. This feature may hinder lithium ion transport. Furthermore, SEM and TEM images of $60 \mathrm{~nm}$ LFP coated at $900^{\circ} \mathrm{C}$ in Ar exhibits large $\mathrm{Fe}_{2} \mathrm{P}$ and LFP particles agglomerated together due to the elevated temperature employed (Supplementary Figs. 4 and 5). Finally, we chose $560 \mathrm{~nm}$ LFP to illustrate the effect $\mathrm{Fe}_{2} \mathrm{P}$ on the electrochemical performance of LFP. Figure 4 a displays the electrochemical performance of $560 \mathrm{~nm}$ LFP particles, following carbon coating under various conditions. Clearly, $560 \mathrm{~nm}$ LFP annealed at $900^{\circ} \mathrm{C}$ has decreased capacity and cycle performance, compared to pure LFP samples, demonstrating only $67 \mathrm{mAh} \mathrm{g}^{-1}$ of capacity after 100 cycles. Two possible reasons may be given for the decreased capacity observed. The first is related to the agglomeration of LFP particles at high temperature, as seen in Supplementary Fig. 4. The second reason is the high content of $\mathrm{Fe}_{2} \mathrm{P}$ phase resulting in decreased lithium conductivity. To verify the influence of $\mathrm{Fe}_{2} \mathrm{P}$ phase content on performance, two $560 \mathrm{~nm}$ LFP samples were prepared by annealing them at $850^{\circ} \mathrm{C}$ for 20 min and $1 \mathrm{~h}$, respectively. The LFP sample annealed at $850^{\circ} \mathrm{C}$ presents less $\mathrm{Fe}_{2} \mathrm{P}$ phase in LFP than $900^{\circ} \mathrm{C}$, as indicated by the XRD pattern in Supplementary Fig. 6, while the sample coated at $800^{\circ} \mathrm{C}$ is pure LFP phase. However, the electrochemical performance of the sample annealed at $850{ }^{\circ} \mathrm{C}$ and $800{ }^{\circ} \mathrm{C}$ demonstrates that the one annealed at a higher temperature results in improved performance. Although the $800^{\circ} \mathrm{C}$-coated LFP sample exhibits a high capacity in the first 60 cycles, the capacity quickly fades. Conversely, after 100 cycles, the $850^{\circ} \mathrm{C}$-coated LFP sample manages to deliver $109 \mathrm{mAh} \mathrm{g}^{-1}$, while the $800^{\circ} \mathrm{C}$-coated LFP only shows $104 \mathrm{mAh} \mathrm{g}^{-1}$, and capacity retention is improved from $88.9 \%$ in $800{ }^{\circ} \mathrm{C}$-coated LFP to $94.0 \%$ in $850^{\circ} \mathrm{C}$-coated LFP. If we reduce the amount of $\mathrm{Fe}_{2} \mathrm{P}$ phase by reducing coating time to $20 \mathrm{~min}$, it results in a large improvement to the electrochemical performance with the sample delivering $125 \mathrm{mAh} \mathrm{g}^{-1}$ after 100 cycles with capacity retention of $100 \%$.

To clarify the influence of $\mathrm{H}_{2}$ gas, $60 \mathrm{~nm}$ LFP annealed in different atmospheric conditions were tested and shown in Fig. 4b. It can be seen that the $60 \mathrm{~nm}$ LFP annealed in Ar shows a stable cycle performance for 100 cycles without capacity decaying. On the contrary, the $60 \mathrm{~nm}$ LFP annealed in $\mathrm{Ar} / \mathrm{H}_{2}$ shows a lower capacity of $140 \mathrm{mAh} \mathrm{g}^{-1}$ in the first cycle and drops to $127 \mathrm{mAh}$ $\mathrm{g}^{-1}$ after 100 cycles, with a retention rate of $90.7 \%$. In order to 

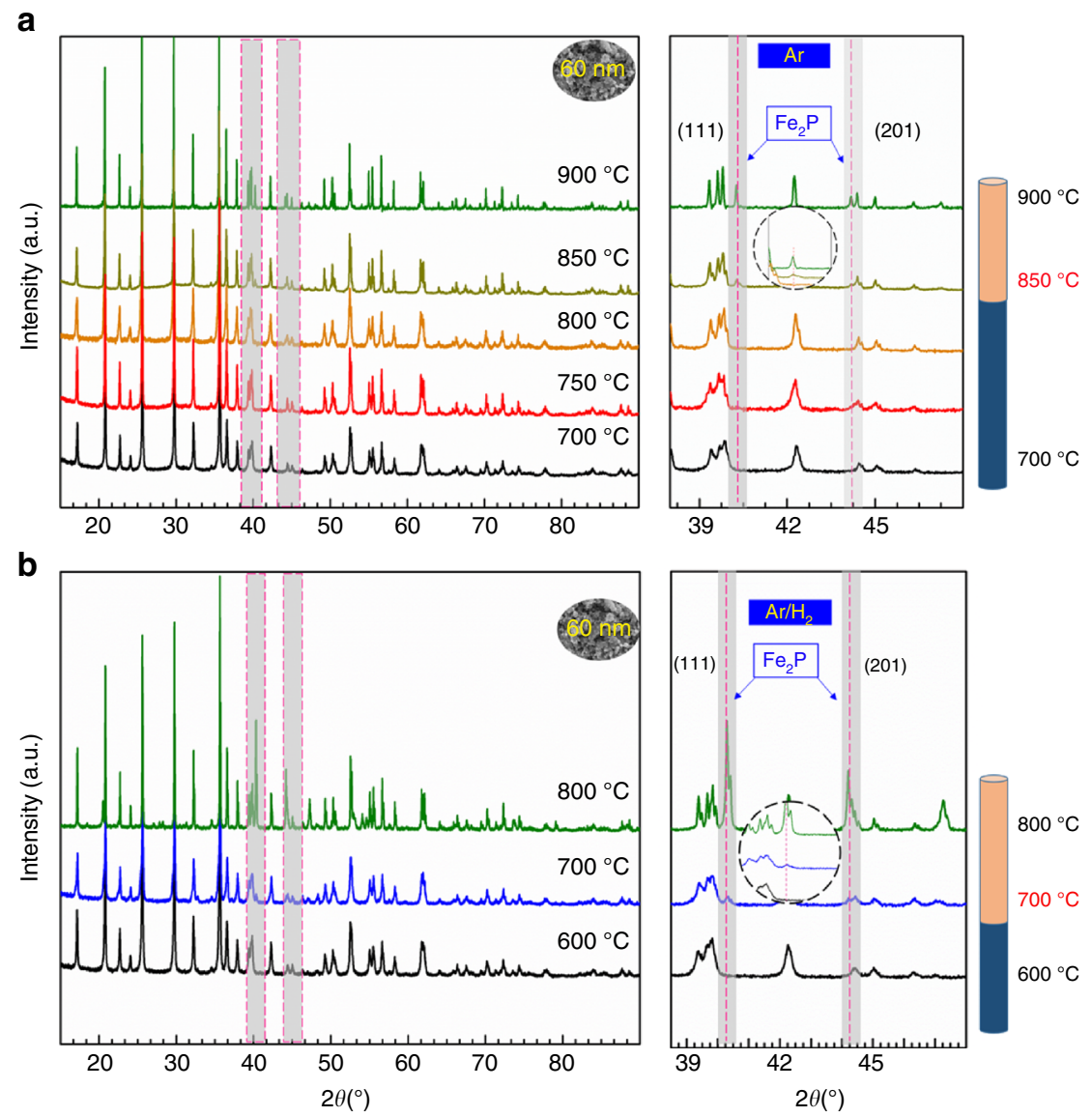

C

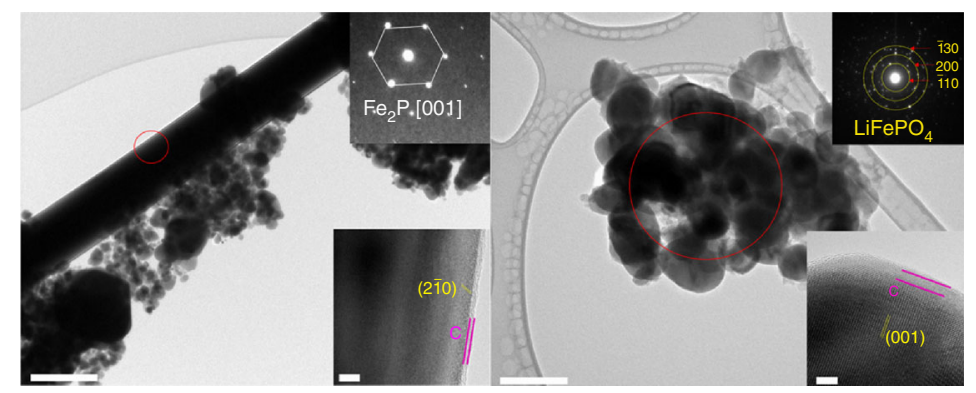

Fig. 3 Temperature dependent and atmosphere dependent properties of $\mathrm{Fe}_{2} \mathrm{P}$ phase formation. a XRD pattern of $60 \mathrm{~nm} \mathrm{LFP}$ after carbon coating in Ar from $700-900^{\circ} \mathrm{C}$. $\mathbf{b}$ XRD pattern of $60 \mathrm{~nm}$ LFP after carbon coating in $\mathrm{Ar} / \mathrm{H}_{2}$ from $600-800^{\circ} \mathrm{C}$. $\mathbf{c}$ TEM characterization of Fe $e_{2} \mathrm{P}$ phase and LFP for $60 \mathrm{~nm}$ LFP annealed in $\mathrm{Ar} / \mathrm{H}_{2}$ (left side) and $\mathrm{Ar}$ (right side) gas at $700^{\circ} \mathrm{C}$. Inset of left picture is the diffraction pattern of Fe ${ }_{2} \mathrm{P}$ phase and $\mathrm{HRTEM}$ images, inset of right picture is the diffraction pattern of LFP phase and HRTEM images. Scale bar, $500 \mathrm{~nm}$ in TEM, $5 \mathrm{~nm}$ in HRTEM in the left picture. Scale bar, $200 \mathrm{~nm}$ in TEM, $5 \mathrm{~nm}$ in HRTEM in the right picture

find the reason, electrochemical impedance spectra of $60 \mathrm{~nm}$ LFP and $560 \mathrm{~nm}$ LFP annealed in $\mathrm{Ar}$ and $\mathrm{Ar} / \mathrm{H}_{2}$ were recorded before cycling (Supplementary Fig. 9 and Supplementary Table 1). It is shown that $60 \mathrm{~nm}$ LFP with addition of $\mathrm{H}_{2}$ gas, a increase of resistance is observed. The high resistance comes from the big size $\mathrm{Fe}_{2} \mathrm{P}$ rod formed in LFP sampled annealed in $\mathrm{Ar} / \mathrm{H}_{2}$, whichblocks the transport of electrons/lithium ions (Fig. 3c). To sum up, these results indicate that carefully controlling $\mathrm{Fe}_{2} \mathrm{P}$ content can increase the capacity of half-cell LFP electrode by improving electronic conductivity and allowing for the formation of a conductive percolating network throughout the electrode (Fig. 4c) ${ }^{20,29,30}$. This improvement can also be attributed to the formation of a lithium pyrophosphate phase $\left(\mathrm{Li}_{4} \mathrm{P}_{2} \mathrm{O}_{7}\right)$ during the carbon coating process, as shown in the Supplementary Fig. 10. Lithium phosphate is known to be a good lithium ion conductor and will aid in improving electrochemical performance ${ }^{31}$.

\section{Discussion}

The formation of conductive $\mathrm{Fe}_{2} \mathrm{P}$ phase has been previously reported by Nazar et $\mathrm{al}^{12}$. However, only EDS information was presented that demonstrated an increased ratio of $\mathrm{Fe} / \mathrm{P}$ at the grain boundary of LFP slices. In a later study published by Chung et $\mathrm{al}^{32}, 3 \mathrm{D}$ phase morphology of $\mathrm{Fe}_{2} \mathrm{P}$ was determined by a combination of electron tomography using high-angle annular dark-field scanning transmission electron microscopy, EDS, and electron energy-loss spectroscopy. However, detailed study regarding phase formation mechanism and control of the secondary phase during carbon coating does not exist. In our work, we demonstrate the importance of carbon coating effect on 
the formation of $\mathrm{Fe}_{2} \mathrm{P}$. Supplementary Figs. 11 and 12 show the surface phase evolution with carbon coating time, with chemical composition changing on LFP ingot, some spherical-like Fe-rich phase is formed on the surface.
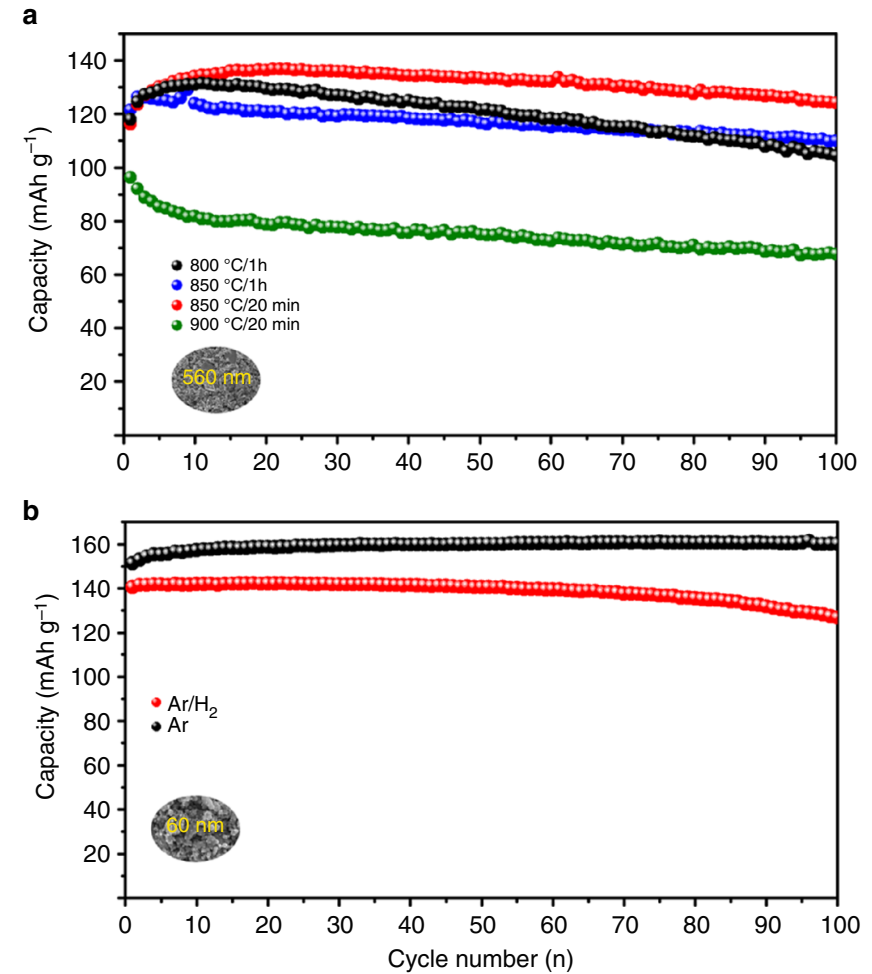

c

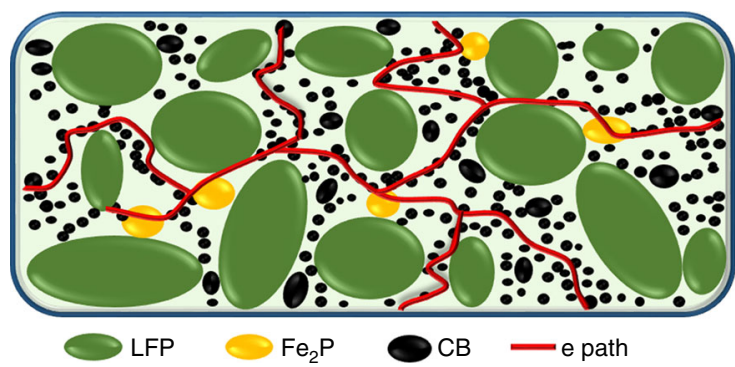

Fig. 4 Positive effect of conductive $\mathrm{Fe}_{2} \mathrm{P}$ phase in LFP. a Electrochemical properties of $560 \mathrm{~nm}$ LFP with different amount of $\mathrm{Fe}_{2} \mathrm{P}$. b $60 \mathrm{~nm}$ LFP annealed in different atmosphere. c Schematic diagram show the positive effect of $\mathrm{Fe}_{2} \mathrm{P}$ with percolation conduction network
Formation of $\mathrm{Fe}_{2} \mathrm{P}$ phase is dependent on size, annealing temperature, and atmosphere, which is ascribed to the interface reaction between surface carbon and underlying LFP phase. Previously, our group proposed a carbon-competitive diffusion/ deposition theory to explain the size-dependent phenomenon of impurity growth in $\mathrm{LFP}^{23}$. The formation of carbon layer on LFP involved a competition of carbon deposition on surface and carbon diffusion into bulk LFP. Smaller particles underwent a high rate of carbon deposition, resulting in rapid encapsulation of the LFP particle with carbon. This resulted in limited carbon diffusion to bulk LFP, leading to a thinner surface reduced layer. On the contrary, bigger particles consumed carbon slowly and had a slow carbon deposition rate, resulting in the carbon atoms being submerged into the crystalline lattice of LFP. Then, the surface of LFP was reduced to a secondary phase. Although this theory allowed us to postulate interface reactions occurring between carbon and LFP, it provides little insight toward the effect of temperature and reducing gas with carbon decomposition. Therefore, we provide a new direction in understanding $\mathrm{Fe}_{2} \mathrm{P}$ phase formation mechanism during carbon coating from a thermodynamic point of view with supporting evidence. (Fig. 5)

Based on the result shown above, $\mathrm{Fe}_{2} \mathrm{P}$ phase formation on LFP during carbon coating maybe expressed as follows:

$$
\begin{gathered}
2 \mathrm{C}_{\mathrm{x}} \mathrm{H}_{\mathrm{y}}=2 \mathrm{xC}+\mathrm{yH}_{2} \uparrow \\
4 \mathrm{LiFePO}_{4}+9 \mathrm{C}=2 \mathrm{Fe}_{2} \mathrm{P}+\mathrm{Li}_{4} \mathrm{P}_{2} \mathrm{O}_{7}+9 \mathrm{CO} \uparrow \\
4 \mathrm{LiFePO}_{4}+9 \mathrm{H}_{2}=2 \mathrm{Fe}_{2} \mathrm{P}+\mathrm{Li}_{4} \mathrm{P}_{2} \mathrm{O}_{7}+9 \mathrm{H}_{2} \mathrm{O} \uparrow
\end{gathered}
$$

The carbon coating process at high temperature involves decomposition of hydrocarbon sources into elemental carbon and reducing gas, accompanied by the formation of $\mathrm{Fe}_{2} \mathrm{P}$ and lithium phosphate at the LFP surface. At moderate temperatures $\left(800{ }^{\circ} \mathrm{C}\right.$ in LFP ingot in Supplementary Fig. 13 and 14), the amount of reducing gas produced is limited, no $\mathrm{Fe}_{2} \mathrm{P}$ is formed. As temperature increases to $875^{\circ} \mathrm{C}$, an increased amount of reducing gas is created and $\mathrm{Fe}_{2} \mathrm{P}$ formation occurs on the surface of LFP, as shown in Supplementary Fig. 13-15. Such a phenomenon is in agreement with first principle calculations performed by Ceder et $\mathrm{al}^{33}$. Their results suggest that $\mathrm{Fe}_{2} \mathrm{P}$ phase formation begins when the oxygen chemical potential $\mu_{o_{2}}=-16.7 \mathrm{eV} \cdot \mu_{o_{2}}$ is determined by temperature and oxygen partial pressure, simultaneously. Higher temperatures, lower oxygen partial pressures and/or the presence of reducing agents corresponds to lower values of $\mu_{o_{2}}$. It can explain the temperature dependent phenomenon of $\mathrm{Fe}_{2} \mathrm{P}$ phase during carbon coating. However, we find that the formation of $\mathrm{Fe}_{2} \mathrm{P}$ phase during carbon coating is

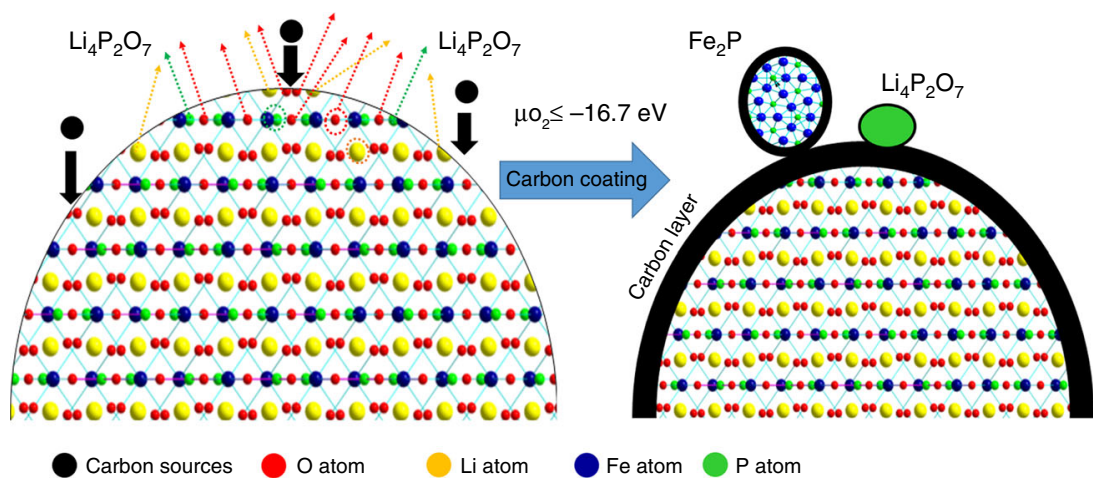

Fig. 5 Oxygen partial chemical potential $\mu \mathrm{O}_{2}$. Schematic illustration of $\mathrm{Fe}_{2} \mathrm{P}$ phase formation during carbon coating process at reducing condition with regards to oxygen partial chemical potential 
dependent not only on temperature, but also on LFP particle sizes.

LFP particles with different sizes exhibiting different catalytic properties on the decomposition of hydrocarbon were reported in our previous paper. The study demonstrated that smaller LFP particles with large surface area facilitated carbon reduction reaction, resulting in an increased reactivity. The Brunauer-Emmett-Teller surface area of LFP particle was measured through $\mathrm{N}_{2}$ adsorption/desorption isotherms tests (Supplementary Fig. 16 and Supplementary Table 2), the results suggested that $\mathrm{Fe}_{2} \mathrm{P}$ formation was closely related to the surface area of LFP particles. In addition, carbon content of LFP particle was measured through TGA tests, and smaller LFP with higher carbon content was observed (Supplementary Fig. 17 and Supplementary Table 3). Thus, with increased surface area for $60 \mathrm{~nm}$ and $560 \mathrm{~nm}$ LFP, the amount of reducing gas produced are increased for smaller LFP particles, leading to a lower $\mu_{o_{2}}$ value compared to larger LFP particles undergoing the same process. As a result, the formation of $\mathrm{Fe}_{2} \mathrm{P}$ phase at $850^{\circ} \mathrm{C}$ for $60 \mathrm{~nm} \mathrm{LFP}$ and $560 \mathrm{~nm}$ LFP is easily attainable. However, for $19 \mu \mathrm{m}$ LFP particle, a temperature of $900^{\circ} \mathrm{C}$ is required for the formation of $\mathrm{Fe}_{2} \mathrm{P}$ phase, suggesting a size-related phenomenon. Based on Ceder's paper, such a $\mathrm{Fe}_{2} \mathrm{P}$ phase change phenomenon was easily observed in Li-rich $\mathrm{LFP}^{33}$. Our inductively coupled plasma atomic emission spectroscopy (ICP-AES) testing (Supplementary Table 4) on LFP particles also confirms that lithium content is higher in smaller LFP samples.

Furthermore, a reducing gas of $\mathrm{Ar} / \mathrm{H}_{2}$ is intentionally introduced during the coating process to create a low oxygen partial pressure $\mu_{\mathrm{O}_{2}}$. As expected, $\mathrm{Fe}_{2} \mathrm{P}$ phase formation occurs readily at a lower temperature of $700{ }^{\circ} \mathrm{C}$ for $60 \mathrm{~nm}$ LFP and $560 \mathrm{~nm}$ LFP, and $800^{\circ} \mathrm{C}$ for $19 \mu \mathrm{m} \mathrm{LFP} \mathrm{in} \mathrm{Ar} / \mathrm{H}_{2}$. To further support our observation, we applied the reducing atmosphere for LFP ingot in the carbon coating process. As shown in Supplementary Fig. 18, the spherical-like iron rich $\mathrm{Fe}_{2} \mathrm{P}$ phase is formed on LFP surface at $800^{\circ} \mathrm{C}$, indicating that $\mathrm{Fe}_{2} \mathrm{P}$ phase formation has been shifted to lower temperature by altering the annealing environment to a more reducing condition. Moreover, the $\mathrm{Fe}_{2} \mathrm{P}$ phase formation is independent of carbon precursor choice as $\mathrm{Fe}_{2} \mathrm{P}$ phase formation occurs in nano-LFP with gas carbon $\left(\mathrm{C}_{2} \mathrm{H}_{4}\right)$ as precursor (Supplementary Fig. 19).

To conclude, we have shown that the formation of surface secondary phase in LFP during carbon coating is dependent on particle size, annealing temperature, and reducing atmosphere. The $\mathrm{Fe}_{2} \mathrm{P}$ phase transformation process is governed by thermodynamic rules and reaction kinetics. In a mild reducing atmosphere of argon gas, $\mathrm{Fe}_{2} \mathrm{P}$ phase is formed at high temperatures for all sizes of LFP, but the critical temperature for phase formation in small LFP is lower. Formation of $\mathrm{Fe}_{2} \mathrm{P}$ phase is closely related to reducing environment during the carbon coating process and is easily formed when the oxygen partial potential $\mu_{\mathrm{O}_{2}}$ is decreased. Our preliminary data from half-cell show a positive effect on electrochemical performance of LFP with presence of $\mathrm{Fe}_{2} \mathrm{P}$ through fine-tuning the phase composition. However, the real impact of cycle life must be evaluated using long-term cycling in a range of temperatures with a full cell format. Nevertheless, method developed in this work may be extended to other olivine phosphate or insulated electrode that undergo carbon coating.

\section{Methods}

Carbon coating on LFP. The LFP ingot sample was provided by Phostech Lithium Inc. (Now, Johnson Matthey, Montreal, Canada), and the carbon coating process followed our previous report ${ }^{23}$.

Here, LFP ingot was used as a starting material and reduced to the appropriate size. An ingot sample was used for two main reasons: first one is its commercial availability providing us with a good baseline for understanding ordinary LFP materials. Second, an ingot offers a flat, smooth, and polished surface that is ideal for observing and investigating surface chemistry changes during carbon coatingfor both the bulk olivine phase and secondary phases. The experimental details regarding melt-casting of LFP ingot can be found in our previous work ${ }^{27,28}$. In order to obtain a flat surface on the ingot, we polished the sample using sandpaper (London, $3 \mathrm{M}$ Canada) ranging from coarse (Grit 120) to fine grade (Grit 1500). Following polishing, the samples were cleaned in an ultra-sonicator using ethanol several times.

LFP ingots were ball-milled into particle with different sizes using $\mathrm{ZrO}_{2}$ balls Size distribution was controlled by ball milling for different times and using different sized $\mathrm{ZrO}_{2}$ balls. The ball milling process used isopropyl alcohol as the media, after the ball-mill process, the obtained precursors were dried in vacuum oven before carbon coating. The particle sizes of LFP were estimated with Image J software by calculating at least 5-10 SEM images.

The carbon-coating experiments on ingot samples were performed in a spraypyrolysis system, which was previously developed for the synthesis of various nanomaterials. In the experiment, alcohol (anhydrous, chemical grade) was directly used as a carbon precursor and $\mathrm{Ar}$ as a carrier and protecting gas. Briefly, the ingot sample with the flat surface facing upward was placed in a quartz tube in $\mathrm{Al}_{2} \mathrm{O}_{3}$ crucibles with a tight seal using vacuums gears. Ar ( $80 \mathrm{sccm}$ ) (or with $\mathrm{H}_{2}, 10 \mathrm{sccm}$ ), was introduced into the quartz tube for $20 \mathrm{~min}$ to eliminate any oxygen and to create an inert environment. Next, the furnace was heated at a heating rate of $5^{\circ} \mathrm{C}$ $\mathrm{min}^{-1}$, and the carbon-coating process was performed at temperatures ranging from $800^{\circ} \mathrm{C}$ to $900^{\circ} \mathrm{C}$ for $20 \mathrm{~min}$. After the carbon coating process at high temperature, the coated sample was cooled to room temperature naturally within the furnace still under the protection of the Ar atmosphere. Samples were collected for further experiments once they were cooled down.

Carbon coating of LFP powders were similar to ingot samples, except that we used the lactose as the carbon sources instead of alcohol. The LFP powders were fully mixed with lactose using water or isopropyl alcohol (carbon source content was $10 \mathrm{wt}$. \%, the concentration was $2 \mathrm{~g} \mathrm{~L}^{-1}$ based on weight of LFP), then the suspension was mixed ultrasonically, and was then allowed to evaporate to dryness. The sample was annealed in $\mathrm{Ar}\left(\right.$ with $\mathrm{H}_{2}$ ) atmosphere at a ramp rate of $5{ }^{\circ} \mathrm{C} \mathrm{min}{ }^{-1}$, from $600{ }^{\circ} \mathrm{C}$ to $900{ }^{\circ} \mathrm{C}$.

Physical characterization. Crystal structure and phase composition of carboncoated LFP were collected using the X-ray diffraction (D8 Advance, Bruker) in the range of $10-90^{\circ}$ with a step of $0.01^{\circ}$ per seconds. Slow scans in the range of $28-33^{\circ}$ were also performed to provide detail on the formation of impurity phases. The carbon-coated LFP powders were subjected to Hitachi 4800 SEM equipped with EDS detector. The working voltage employed for EDS mapping was $20 \mathrm{kV}$. The Raman spectra were conducted at HORIBA Scientific LabRAM with a laser $(\lambda=$ $532.3 \mathrm{~nm}$ ) as the excitation source. Raman spectroscopy maps from at the sample were collected in autofocus mode with a spatial resolution of ca. $2 \mu \mathrm{m}$. The detailed structure of carbon-coated LFP particles are investigated by HR-TEM (JEOL 2010 FEG) operating at an accelerating voltage of $20 \mathrm{kV}$, diffraction patterns were recorded using the SAED mode. Thermo-gravimetric analysis (TGA) was carried out on a TA SDT Q600 in an air atmosphere from room temperature to $900{ }^{\circ} \mathrm{C}$ at a rate of $10 \mathrm{C} \mathrm{min}-1 . \mathrm{N}_{2}$ adsorption/desorption isotherms of LFP particles were performed using a Folio Micromeritics TriStar II Surface Area and Pore Size Analyzer.

Electrochemical tests. The electrochemical performance of carbon-coated LFP were tested in 2032 coin cells, using a Li metal foil as a counter electrode. The electrode is composed of $80 \mathrm{wt} . \%$ carbon-coated LFP as active material, $10 \mathrm{wt} \%$ $\mathrm{PvDF}$ as binder, and $10 \mathrm{wt} . \%$ carbon black as conductive agent, with an active material loading of $1.5-2 \mathrm{mg} \mathrm{cm}^{-2} .1 \mathrm{M} \mathrm{LiPF}_{6}$ in EC, DEC, and EMC with a volume ratio of 1:1:1 was employed as an electrolyte along with Celgard 2400 as a separator. The cells were assembled in an Ar-filled glove box with oxygen and water levels below 1 ppm. Charge-discharge cycling using a constant current mode was performed on an Arbin BT-2000 Battery Test System. All the electrochemical measurements were carried out in a voltage range of $2.2-4.2 \mathrm{~V}$ at RT.

Data availability. The data that support the findings of this study are available from the corresponding author upon request.

Received: 10 October 2017 Accepted: 5 February 2018 Published online: 02 March 2018

\section{References}

1. Padhi, A. K., Nanjundaswamy, K. S. \& Goodenough, J. B. Phospho olivines as positive electrode materials for rechargeable lithium batteries. J. Electrochem. Soc. 144, 1188-1194 (1997).

2. Wang, J. \& Sun, X. Olivine $\mathrm{LiFePO}_{4}$ : the remaining challenges for future energy storage. Energy Environ. Sci. 8, 1110-1138 (2015). 
3. Wang, Y., He, P. \& Zhou, H. Olivine $\mathrm{LiFePO}_{4}$ : development and future. Energy Environ. Sci. 4, 805-817 (2011).

4. Wang, J. \& Sun, X. Understanding and recent development of carbon coating on $\mathrm{LiFePO}_{4}$ cathode materials for lithium-ion batteries. Energy Environ. Sci. 5, 5163-5185 (2012).

5. Herstedt, M. et al. Surface chemistry of carbon-treated $\mathrm{LiFePO}_{4}$ particles for Li-ion battery cathodes studied by PES. Electrochem. Solid State Lett. 6, A202-A206 (2003).

6. Wilcox, J. D., Doeff, M. M., Marcinek, M. \& Kostecki, R. Factors influencing the quality of carbon coatings on $\mathrm{LiFePO}_{4}$. J. Electrochem. Soc. 154, A389-A395 (2007).

7. Chen, L., Yuan, Y. Q., Feng, X. \& Li, M. W. Enhanced electrochemical properties of $\mathrm{LiFe}_{1-\mathrm{x}} \mathrm{Mn}_{\mathrm{x}} \mathrm{PO}_{4} / \mathrm{C}$ composites synthesized from $\mathrm{FePO}_{4} \cdot 2 \mathrm{H}_{2} \mathrm{O}$ nanocrystallites. J. Power Sources 214, 344-350 (2012).

8. Oh, S. W. et al. Double carbon coating of $\mathrm{LiFePO}_{4}$ as high rate electrode for rechargeable lithium batteries. Adv. Mater. 22, 4842-4845 (2010).

9. Wang, J. et al. Interaction of carbon coating on $\mathrm{LiFePO}_{4}$ : A local visualization study of the influence of impurity phases. Adv. Funct. Mater. 23, 806-814 (2013).

10. $\mathrm{Yu}, \mathrm{D}$. Y. W. et al. Impurities in $\mathrm{LiFePO}_{4}$ and their influence on material characteristics. J. Electrochem. Soc. 155, A526-A530 (2008).

11. Trudeau, M. L. et al. In situ high-resolution transmission electron microscopy synthesis observation of nanostructured carbon coated $\mathrm{LiFePO}_{4}$. J. Power Sources 196, 7383-7394 (2011)

12. Herle, P. S., Ellis, B., Coombs, N. \& Nazar, L. F. Nano-network electronic conduction in iron and nickel olivine phosphates. Nat. Mater. 3, 147-152 (2004).

13. Kang, B. \& Ceder, G. Battery materials for ultrafast charging and discharging. Nature 458, 190-193 (2009).

14. Wagemaker, M., Ellis, B. L., Lutzenkirchen-Hecht, D., Mulder, F. M. \& Nazar, L. F. Proof of supervalent doping in olivine $\mathrm{LiFePO}_{4}$. Chem. Mater. 20 6313-6315 (2008).

15. Chung, S. Y., Choi, S. Y., Kim, T. H. \& Lee, S. Surface-orientation-dependent distribution of subsurface cation-exchange defects in olivine-phosphate nanocrystals. ACS Nano 9, 850-859 (2015).

16. Paolella, A. et al. Cation exchange mediated elimination of the Fe-antisites in the hydrothermal synthesis of $\mathrm{LiFePO}_{4}$. Nano Energy 16, 256-267 (2015).

17. Paolella, A. et al. Accelerated removal of Fe-antisite defects while nanosizing hydrothermal $\mathrm{LiFePO}_{4}$ with $\mathrm{Ca}^{2+}$. Nano. Lett. 16, 2692-2697 (2016).

18. Xu, Y., Lu, Y., Yan, L., Yang, Z. \& Yang, R. Synthesis and effect of forming $\mathrm{Fe}_{2} \mathrm{P}$ phase on the physics and electrochemical properties of $\mathrm{LiFePO}_{4} / \mathrm{C}$ materials. J. Power Sources 160, 570-576 (2006).

19. Lin, Y., Gao, M. X., Zhu, D., Liu, Y. F. \& Pan, H. G. Effects of carbon coating and iron phosphides on the electrochemical properties of $\mathrm{LiFePO}_{4} / \mathrm{C}$. J. Power Sources 184, 444-448 (2008).

20. Song, M. S. et al. Amphoteric effects of $\mathrm{Fe}_{2} \mathrm{P}$ on electrochemical performance of lithium iron phosphate-carbon composite synthesized by ball-milling and microwave heating. J. Power Sources 180, 546-552 (2008).

21. Yin, Y. et al. High-rate capability of $\mathrm{LiFePO}_{4}$ cathode materials containing $\mathrm{Fe}_{2} \mathrm{P}$ and trace carbon. J. Power Sources 199, 256-262 (2012).

22. Zhang, L. et al. Synthesis of $\mathrm{Fe}_{2} \mathrm{P}$ coated $\mathrm{LiFePO}_{4}$ nanorods with enhanced Listorage performance. J. Alloy. Compd. 627, 132-135 (2015).

23. Wang, J. et al. Size-dependent surface phase change of lithium iron phosphate during carbon coating. Nat. Commun. 5, 3415-3423 (2014).

24. Zaghib, K., Mauger, A., Gendron, F. \& Julien, C. Surface effects on the physical and electrochemical properties of thin $\mathrm{LiFePO}_{4}$ particles. Chem. Mater. 20, 462-469 (2007).

25. Julien, C. M., Mauger, A. \& Zaghib, K. Surface effects on electrochemical properties of nano-sized $\mathrm{LiFePO}_{4}$. J. Chem. Mater. 21, 9955-9968 (2011).

26. Kayyar, A., Qian, H. \& Luo, J. Surface adsorption and disordering in $\mathrm{LiFePO}_{4}$ based battery cathodes. Appl. Phys. Lett. 95, 221905-221908 (2009).
27. Gauthier, M. et al. Melt casting $\mathrm{LiFePO}_{4}$ I. Synthesis and characterization. J. Electrochem. Soc. 157, A453-A462 (2010).

28. MacNeil, D. et al. Melt Casting $\mathrm{LiFePO}_{4}$ II. particle size reduction and electrochemical evaluation. J. Electrochem. Soc. 157, A463-A468 (2010).

29. Liu, Y., Cao, C., Li, J. \& Xu, X. A novel synthesis of $\mathrm{Fe}_{2} \mathrm{P}-\mathrm{LiFePO}_{4}$ composites for Li-ion batteries. J. Appl. Electrochem 40, 419-425 (2010).

30. Kang, H. C. et al. Optimized solid-state synthesis of $\mathrm{LiFePO}_{4}$ cathode materials using ball-milling. J. Power Sources 179, 340-346 (2008).

31. Rho, Y. H., Nazar, L. F., Perry, L. \& Ryan, D. Surface chemistry of $\mathrm{LiFePO}_{4}$ studied by Mössbauer and X-ray photoelectron spectroscopy and its effect on electrochemical properties. J. Electrochem. Soc. 154, A283-A289 (2007).

32. Chung, S. Y., Kim, Y. M. \& Choi, S. Y. Direct physical imaging and chemical probing of LiFePO4 for Lithium-Ion batteries. Adv. Funct. Mater. 20, 4219-4232 (2010)

33. Ong, S. P., Wang, L., Kang, B. \& Ceder, G. Li-Fe-P-O $\mathrm{O}_{2}$ phase diagram from first principles calculations. Chem. Mater. 20, 1798-1807 (2008).

\section{Acknowledgements}

This work was supported by the Natural Sciences and Engineering Research Council of Canada (NSERC), Automotive Partnership of Canada Program, Johnson Matthey (Previous Phostech Lithium Inc.), Canada Research Chair (CRC) Program, Canadian Light Source (CLS), McMaster Microscopy Centre for HRTEM, and Western University.

\section{Author contributions}

X.S. conceived the overall project; Y.L. designed/performed the experiments, data analysis, and wrote the manuscript; J.L., J.W., and B.X. helped with carbon-coating experiment; M.N.B. and A.L performed XRD characterization; R.L. helped with TEM characterization and discussion; M.N.B, W.X., and T.K.S. performed synchrotron characterization and discussion; G.L. and X.S. interpreted the results.

\section{Additional information}

Supplementary Information accompanies this paper at https://doi.org/10.1038/s41467 018-03324-7.

Competing interests: The authors declare no competing interests.

Reprints and permission information is available online at http://npg.nature.com/ reprintsandpermissions/

Publisher's note: Springer Nature remains neutral with regard to jurisdictional claims in published maps and institutional affiliations.

Open Access This article is licensed under a Creative Commons Attribution 4.0 International License, which permits use, sharing, adaptation, distribution and reproduction in any medium or format, as long as you give appropriate credit to the original author(s) and the source, provide a link to the Creative Commons license, and indicate if changes were made. The images or other third party material in this article are included in the article's Creative Commons license, unless indicated otherwise in a credit line to the material. If material is not included in the article's Creative Commons license and your intended use is not permitted by statutory regulation or exceeds the permitted use, you will need to obtain permission directly from the copyright holder. To view a copy of this license, visit http://creativecommons.org/ licenses/by/4.0/

(C) The Author(s) 2018 